\title{
Ekphrastic Historiographic Metafiction - Enfolding Word, Image and History
}

\begin{abstract}
The purpose of this paper is to provide a dynamic model of ekphrasis which can be used to interpret literary works that refer to, and thus, represent works of art. The paper will also show how ekphrasis as a fold collaborates with historiographic metafiction in ekphrastic historiographic metafiction. Theoretical reflection will be illustrated with the relevant examples from Salman Rushdie's The Enchantress of Florence, Patrick Gale's Notes from an Exhibition, Tracy Chevalier's Girl with a Pearl Earring and Joseph Heller's Picture This.

Keywords: ekphrasis, fold, historiographic metafiction, ekphrastic historiographic metafiction, Patrick Gale, Salman Rushdie, Tracy Chevalier, Joseph Heller
\end{abstract}

\section{Introduction}

The history of the relationship between word and image is a long and complex one, for its origins can be traced back to the ancient times and the beginnings of art, literature and rhetoric (Heffernan, 1993; Hagstrum, 1987; Praz, 1974). Painting and literature have inspired each other for centuries. Painters illustrated or depicted stories they heard or read, and poets/writers described works of art they saw and admired, or simply imagined. From its very beginning, the academic debate on the nature of the relationship between poetry and painting, or the visual and the verbal in general, has been divided into two opposing positions. On the one hand, there is the approach supporting the paragone, i.e., the definite separation, unresolved rivalry and continuous struggle for domination between word and image, visible in the theories put forward by the followers of Leonardo da Vinci or Gotthold Ephraim Lessing. On the other hand, there is the sister arts approach, which focuses on the similarities and the cooperation between the visual and the verbal, manifested in the Horatian doctrine of ut pictura poesis.

The question considered in this paper concerns the existence of a third option that would resolve the paragone and focus on the complementary nature and inseparability of word and image, especially regarding the problem of representing history in contemporary literature in English. Hence, the purpose of the article is

Dominika Bugno-Narecka, Katedra Literatury i Kultury Amerykańskiej, Katolicki Uniwersytet Lubelski Jana Pawła II, Al. Racławickie 14, 20-950 Lublin, dominika.bugno-narecka@kul.pl, https://orcid.org/0000-0003-4230-3379 
to examine how literature uses works of art, especially paintings, to write and tell (hi)story. The approach adopted here will follow neither the paragone nor the sister arts approach, but will attempt to establish a new thread in the study of word-image relationships. Theoretical reflection on the use of non-binary ekphrastic description in novels describing fictionalised history will be illustrated with examples of ekphrasis from four novels: Salman Rushdie's The Enchantress of Florence (2008), Patrick Gale's Notes from an Exhibition (2007), Tracy Chevalier's Girl with a Pearl Earring (1999) and Joseph Heller's Picture This (1988). It will be demonstrated here how the descriptions of artworks can be used by historiographic metafiction understood as the writing of and about history by means of literary fiction.

\section{Theoretical reflection}

In order to determine the third way mentioned above, it is necessary to leave the post-Cartesian system of body-mind dichotomies for an alternative to the omnipresent ideal-material distinction. The alternative in question, provided by Gottfried Wilhelm Leibniz and later developed by Gilles Deleuze and Anna Munster, is comprised of the notion of the fold. In Leibniz's view, all matter consists of an infinite continuum of elastic texture which folds into smaller and smaller folds. Within these countless folds there is no final indivisible point. Furthermore, due to different forces at play, matter also forms inner folds, which are distinct from the outer ones, but which belong to the very continuum and are part of the same unity. Consequently, the unity of matter points to another layer that of the soul - which is further subject to the process of folding and unfolding.

Leibniz, Deleuze and Munster perceive the universe as an endless process of folding and unfolding the outside (matter) that creates an inside (soul) which, in turn, is the doubling of the outside. In other words, the world consists of the physical axis of material bodies and the metaphysical sphere of free souls which are both separate yet connected through folding. As a result, everything that exists is folded in-between: it constitutes "a fold-of-two" (Deleuze, 1993, p. 10), i.e., a fold-of-material-and-immaterial. As ideas are imbued with the material realisations of these ideas, they all form an infinite continuity. Consequently, fold is a hybrid which allows to explain the material and the immaterial reality. It is impossible to know the material without the presence of the immaterial.

One distinctive feature of the fold is that it "is both confluent and dissonant: it joins sides and marks the difference between them" (Munster, 2006, p. 31). Thus, the elements within the fold, or its sides, remain distinct but are inseparably connected as they belong to a continuum. What is folded is "at the very same instance different and the same" (Seppi, 2016, p. 52) - it differentiates and is differentiated (Deleuze, 1993, p. 30). As the structure of the fold is always double, it is impossible to suppress one side of the fold without the other being 
suppressed as well (Teyssot, 2000, p. 79). According to West-Pavlov (2009), " $t \mathrm{t}]$ e fold is Deleuze's most genial solution to resolving the paradox of simultaneous indivisibility and multiplicity" (p. 233). The fold not only suggests but also imposes continuity, which eliminates the principle of the excluded middle and deconstructs binary oppositions. In this model, binary oppositions may constitute the two extremes or ends of the fold. Since they belong to the spectrum of the fold, mentioning of one extreme immediately evokes the presence of the other extreme.

In such a model of reality, then, it can be said that the fold joins word and image and, at the same time, marks the difference between them. Consequently, it can be argued that the paragone is solved - the elements are equally important and the binary opposition is lifted or deconstructed as the verbal and the visual elements constitute the ends of the fold and its extension in either direction.

The problem of the enfolded word and image is perhaps best illustrated by the notion of ekphrasis. The scope of the notion, i.e. whether ekphrasis is exclusively a poem about a painting or a description of any work of art (representational or non-representational) or any non-verbal text (kinetic or non-kinetic), and whether it is a separate work or part of a longer narrative, has been constantly debated and various scholars have adopted different definitions of the notion in their studies. For the purposes of this analysis, however, the definition of ekphrasis provided by Clüver (2017) in Ekphrasis and Adaptation seems to be the most appropriate. $\mathrm{He}$ understands ekphrasis as "the verbal representation of real or fictive configurations composed in a non-kinetic visual medium" (p. 462). His definition is broader than Heffernan's (1993) more popular "verbal representation of visual representation" (p. 3) as it includes descriptions of non-representational art, like architecture, sculpture or abstract art. At the same time, Clüver's definition is narrow enough to exclude instances of pictorialism and iconicity, which also belong to the general fold of word and image relationships, or the descriptions of dance, film and television.

The intuition that the verbal and the visual are inseparable, like the whole history of word and image relationships, goes back to the roots of ekphrasis and to the ancient art of rhetoric, which perceived ekphrasis as "a descriptive account bringing what is illustrated vividly before one's sight" (Heffernan, 1991, p. 312). The translatability of one code into another is inscribed in the etymology of the word: Greek ek phrazein, which literally means "to tell in full" or "to speak out". The linguistic precision and flexibility as well as the fluency of ekphrastic description transform the listener/reader into a spectator as the language of the description creates a picture in the imagination of the listener/reader. Consequently, the vivid language of description (word) immediately points to the existence of a specific visual structure (image). This feature of ekphrasis is referred to by rhetoricians as enargeia, and it strongly suggests a dynamic vision of the notion in which the distinction between the verbal and the visual is blurred and the two are 
folded together into a single structure. Führer and Banaszkiewicz (2014) notice that rhetorical ekphrasis is a

device surpassing the traditional narratological classifications of description and narration as well as the generalising semiotic categories of word and image when considered as two conventionally distinct media of oppositional character (p. 55).

As far as literary ekphrasis is concerned, Wagner (1996) claims that because literature and art occupy "the same representational space", there is no "line separating the visible from the readable" (pp. 32-33), which matches Deleuze's idea of a smooth transition from seeing to reading the unfolding world. According to Smith, the unconstrained transition between word and image is possible due to the instability of the relation between word, idea and thing. Although the correspondence theory of literary description assumes a stable and invariable reference, and a clear relation between the signifier and the signified, structuralism brings the idea of connotation, which destabilises the fixed relationship between the sign and its referent: "connotative references behind the denotative sign constantly remind one of the instability of communicative and reading acts that are always subject to supplementation or substitution" (Smith, 1995, p. 4). In the processes of communication and reading, new supplementary meanings of signs are created by means of connotation. What is more, some already existing meanings of signs can be replaced with others. This does not change the fact that there are certain contextual determinants that limit the meaning of a sign by indicating a relation between the sign and a singular external referent. Still, ekphrasis foregrounds "linguistic debates over truth-claims of referential and linguistic paradigms, making language their primary theme" (Smith, 1995, p. 12). It happens so due to the tensions between two competing theories of truth: correspondence theory and coherence theory. According to the former, there is a logical empirical link between language and reality. The latter, in turn, claims that language is a "rational system containing analogical truths that fit the experiential world" (Smith, 1995, p. 23). As a result, language is the instrument of world-making.

By analogy, the relationship between correspondence and coherence can be compared to the tension between the visual and the verbal, the two modes of representation present in the notion of ekphrasis. The analogy is particularly visible when we juxtapose Smith's (1995) observation that "[t]he consistent use of ekphrasis [...] reveals a regular pattern of literary struggle between the conflicting correspondence and coherence paradigms of representation" (p. 15) with Heffernan's (1996) statement that ekphrasis "stages a battle for mastery between two rival systems of representation" (p. 263): the driving force of the verbal code and "the stubborn resistance" of the fixed visual code. Smith (1995) further explains that "in order to establish truth-claims for a valorized paradigm of representation, the texts must represent both discourses, and this act 
of representation undermines any obvious attempt to deny the representational efficacy of the opposing paradigm" (p. 38). In other words, both correspondence and coherence, or referentiality and performativity, are present side by side in a literary work. Neither of them is the privileged or the favoured one, and thinking of one immediately makes the other present. As a result, stability is absent and the denotation which governs the sign-referent relation becomes ambiguous. Without a stable and predominant foundation, meaning is a play of differences and depends on what is present and what is absent.

Similarly, the verbal and the visual elements in ekphrasis are equally valid and significant. Each element bears a trace of the other. The features of a text or a configuration in a non-verbal sign system can be extended onto the verbal representation of it and vice versa: the properties of the verbal representation entail and can be extended onto the visual. The verbal implies the visual and the visual bears marks of the verbal, even if the other element seems to be absent. Such configuration opens ekphrasis to connotation which, as mentioned above, frequently resorts to substitution and supplementation. Consequently, ekphrasis seems to be incomplete and capable of continuation. Indeed, it can be further extended by means of another fold that might include, for instance, the world presented in the story, a part of which is constituted by the configuration composed in a non-verbal sign system described verbally.

The morphology of ekphrasis outlined above leads to and allows for the distinction of ekphrastic historiographic metafiction, which is the extension of the notion of ekphrasis onto the issues related to representing history in literary works. Hutcheon (1988) in A Poetics of Postmodernism: History, Theory, Fiction explains the way postmodernist thinking challenges the separateness of the historical and the literary. She observes that instead of being separate and individual, history and literature in fact share a particular set of features. According to Hutcheon (1988), history and literature "derive their force more from verisimilitude than from any objective truth" (p. 105). Both are "linguistic constructs, highly conventionalized in their narrative forms", and "equally intertextual, deploying the texts of the past within their own complex textuality" (p. 105). Currie (2013) in a short foreword to Hayden White's "The Question of Narrative in Contemporary Historical Theory" notices that "just as historical theory finds its way into narrative, so too does narrative find its way into history" (p. 104). Hence, the influence is both mutual and reciprocal. As a result, in historiographic metafiction there is a constant tension between the historical (be that figures, settings or events) and the fictional. The line between the two is blurred.

In addition, according to Hutcheon (1988), "[h]istoriographic metafiction acknowledges the paradox of the reality of the past but its textualized accessibility to us today" (p. 114). Because there is no access to historical reality, only a plausible version of history can be mediated and reconstructed. Historical 
texts do not describe or trace history as it is or as it happened ("the reality of the past"), but propound a possible version of history ("textualised accessibility"). Indeed, Hutcheon (1988) states that "we can only know 'reality' as it is produced and sustained by cultural representations of it" (p. 121). Actual ekphrasis, i.e., a description of a non-verbal text which exists independently outside the literary work, is precisely a cultural representation of 'reality'. But the problem is more complex than that. Ekphrasis can be used to bridge the gaps in the story or history told. In other words, it can fill in the missing details or provide new information in the story, like in Salman Rushdie's The Enchantress of Florence or Patrick Gale's Notes from an Exhibition. At the same time, ekphrasis can be the trace or the remnant of the past which in itself contains gaps and triggers questions and speculations about the unknown or unrecorded aspects of history. As such, it can be the starting point for telling the story and providing a fictional account of the events related to the authentic visual material. That is the case of, for instance, Joseph Heller's Picture This or Tracy Chevalier's Girl with a Pearl Earring. The two approaches and the four novels will be now briefly considered in the analytical part of this paper.

\section{Practical application}

The first of the two ways in which historiographic metafiction can use ekphrasis is to bridge the gaps in the story and in the plausible version of historical events proposed by the author. Ekphrastic descriptions can be smoothly, even seamlessly, incorporated into the narrative and might play an important role in the construction of a coherent plot. Ekphrases that describe Dashwanth's paintings in Rushdie's The Enchantress of Florence constitute significant integral elements of the complex narrative. They intertwine with the historical narrative, regardless of whether history is understood as historical fact, like battles and wars of which some historical record remains; or an invented story set in a particular historical context, like the story of Qara Köz and her adventures. In other words, a verbal account of the visual depiction mingles with the (fictitious) past reconstructed in language and contributes to the rewriting of history. As can be noticed in the extensive ekphrasis concerning the painting of the fall of Umar Sheikh Mirza (Rushdie, 2009, pp. 153154), the description of the painting overlaps with the historical account and the other way round, history extends onto an ekphrastically presented work of art. This means that the description of the artwork evokes historical figures and events, and historical account points to the artwork. In particular, the fall of Akbar's ancestor is a historical fact, known to the members of the royal family and preserved in the sources outside the novel. But, in addition to the physical appearance of Umar Sheikh, who is depicted in the painting as fat and short, the character of Akbar's relative - good-natured, just and talkative backgammon player and wine-lover - is also deftly woven into the literary description of the picture. The description of 
the depiction naturally goes beyond the image and smoothly moves on to include Umar Sheikh's descendants and warns them not to follow in the ancestor's steps (Rushdie, 2009, p. 154). The painting and its description help (re)construct and interpret historical events they attempt to depict.

The same can be said about the descriptions of Dashwanth's series of paintings depicting Qara Köz's life (pp. 149-160). The paintings, and their subsequent descriptions, are based on the verbal account provided by Niccolo, one of the protagonists. The artworks aim at representing, and hence (re)constructing, the image of the forgotten princess. Together with Niccolo's narrative, the artworks fill the gap in the memory of the princess's family. Set in the elaborately described and minutely depicted landscape of the early Mughal empire, the paintings show Qara Köz at different stages of her childhood and adolescence until her departure with the Shah of Persia. The paintings (re)present the long forgotten past: ancestors, cities and landscapes of the past spring back to life on canvases described. What is worth emphasising is that all the descriptions of Dashwanth's paintings imply and include the events from the princess's life before and after the scenes represented on canvas; hence, narrative mingles seamlessly with description. The Mughal princess, Qara Köz, is brought back to life because by looking at the paintings the royal ladies suddenly remember the name of the forgotten princess and re-consider her existence: "The painting itself worked a kind of magic, because the moment old Princess Gulbadan looked at it in Akbar's private rooms she remembered the girl's name, $[\ldots]$ 'Makhdum, yes, that was the mother's name [...]. And the girl was Qara Köz! - Qara Köz, that was it!'” (p. 150). It can be said that the paintings, after recalling forgotten and repressed history, restore the princess to the memory of her family. Ekphrastic passages in Rushdie's novel show history and art as a continuum and illustrate how the fold functions: the border between the two notions, history and art, is blurred and made invisible on the pages of the novel. There is a smooth transition from the work of art to history, i.e., from the description of the work of art to the narration of historical events and the other way round: from the verbal account of history to the description of its visual representation. The two forms extend onto and complement each other.

In Notes from an Exhibition, Gale organises the structure of the novel around a collection of exhibit labels - each chapter begins with a curatorial note which introduces a new exhibit and a new non-chronological fragment of the story. The intuition that these descriptions are separate from the narrative that follows because of the visible frame seems utterly wrong. Not only do the items described at the beginning of each chapter appear later in the narrative which is told from the points of view of different members of the family; but the exhibits also point to other items on display in the novel. For instance, a swimming costume, one of the exhibits described in the label at the beginning of the fourth chapter, matches in colour with two landscape paintings mentioned in that label. The item itself is 
used in the narrative that follows by the artist during one of many picnics on the beach. All the items gathered for the literary exhibition - works of abstract art and private possessions - together with the curatorial notes that describe them and the narrative that accompanies each item (re)construct and (re)create the story of Rachel Kelly, an imaginary painter, her bipolar disorder and artistic activity, as well as the story of her family. The relationship between the objects on display is that they reflect stages of the artist's and her family's life, and complement the narrated fragments of the story, e.g., early works correspond to the early years of Rachel's life, clothes match the occasion on which they are worn and which is later described in the novel. Ekphrases not only complement but also unite the otherwise fragmented narrative provided by the members of Rachel's family and their shredded memories. Due to the consistent strategy of opening each chapter with an exhibit description, ekphrases become the binder of the multiperspective narrative, bringing together an array of viewpoints and scattered pieces of information.

The other approach to using ekphrasis in historiographic metafiction concerns the work of art as the starting point for the story. Here, the artwork precedes the story and frequently the depicted figures become the protagonists of such a story. A perfect example of this approach is Chevalier's Girl with a Pearl Earring. The writer's personal obsession with the painting, as well as scarce information about Vermeer's life and no record of the model's identity, led to fictitious speculations about the model's history (a Protestant maid working in one of Catholic households in the $17^{\text {th }}$ century Delft) and the story of the painting's origin (a commission from a wealthy patron and the artist's attempt to avoid social scandal). The novel can be regarded as a supplement to the painting, a supplement which blends fiction with history. The existence and actions of Vermeer, his family and patrons might be proved and documented, i.e. there are records of where they went and what they did, but no personal content remains. Consequently, Chevalier could put plausible words into their mouths, suggest plausible motives for their actions and for Vermeer's paintings, and speculate about the model for Girl with a Pearl Earring, her social background, thoughts, feelings and interaction with the artist. Thus, the whole novel can be considered not only as one extensive ekphrasis pointing to the events before and after the scene depicted in the eponymous painting, but also as a story built on ekphrastic descriptions of Vermeer's other works, including View of Delft, Woman with a Perl Necklace, The Concert and a couple of others. These paintings capture the reality of the time and place of their creation, i.e., Vermeer's household and baroque Dutch city, and determine the aesthetics and constraints of the novel's plot, e.g., Griet's thoughts and behaviour, descriptions of the setting, or social conventions.

Another example of a novel adopting the second approach is Heller's Picture This, in which the very distant and the very recent past seem to merge in Rembrandt's 
painting Aristotle Contemplating a Bust of Homer. The painting and the description of the painting, as well as the fictionalised history of its creation and successive possession, are the starting point for a lengthy meditation on history, philosophy and culture that spans many centuries: from the antiquity long before Aristotle was represented in Rembrandt's painting, through the history of the Netherlands, especially during the period of Rembrandt's life, to the $20^{\text {th }}$ century and the tense relations between the US and Russia during the Cold War. Ekphrasis is extended from what is widely known (or what is thought to be widely known) to what is not known (that can be guessed or presumed). It includes the story, i.e. a literary account that suggests a particular version of events, of the figures depicted by Rembrandt, the painter himself and the story of Aristotle Contemplating a Bust of Homer's possession, which, in turn, are extended or unfold to include a great number of other facts, such as references to, and descriptions of, Rembrandt's other paintings, which are presented in a wider context of events and figures:

In May of 1656 he [Rembrandt] transferred the house to Titus. He was safe from jail but penniless.

In Amsterdam a man could be executed for stealing a coat and invited to city hall after stealing a fortune.

Shares in the Dutch East India Company plummeted too.

The house went up for auction in 1658, the same year he completed the majestic self-portrait now in the Frick Collection in New York, in which, lushly attired in a fur mantle and a gown of gold, he sits in a chair as though filling a throne, rests his fingers around a silver-topped cane that could be a scepter, and looks as regal, perhaps, as Mr. Henry Clay Frick, of the steel industry, did himself, as baronial, perhaps, as Frick, Cornelius Vanderbilt, Henry Ford, John Pierpont Morgan and Lorenzo de'Medici rolled into one (Heller, 1988, pp. 247-248).

In a way, Picture This could be read as a literary Wunderkammer accumulating many descriptions of objects and facts that attempt to explain the world and the rules that govern it, mainly economic and political, though not exclusively.

What is more, a possible literary explanation of how the meaning was bestowed on the painting is provided in the form of a dialogue between Rembrandt and Jan Six:

"I don't recognise the man. Is it someone I should?"

"Aristotle."

"He looks like a Jew."

Aristotle glared. Rembrandt toned him right down with a small touch of glaze.

"It's the way I want him. [...] A friend models for me."

"In that costume? Aristotle?"

"Don't you like the effect?"

"He looks so sad."

"It's the way that I see him. He is growing older. He doesn't know what to do. He's an ancient philosopher and he can't find work."

"Do I see something else? Is that a face on the pendant now?" 
"I'm putting one in. I don't know whose it is. It's from something I bought."

"Call it Alexander the Great." "Why?"

"He was taught by Aristotle. You'll get credit for greater symbolic intelligence. The gold in the chain?"

"I'm making it thicker" (Heller, 1988, p. 66).

The figure painted by the artist is that of Aristotle but with a Jewish physical appearance. The man on the medallion is now recognised as Alexander the Great while it is suggested that for Rembrandt it could have been anyone. The form of the dialogue about the painting in which one character challenges the other, instead of the tedium of a minute description, indicates the creative and pronarrative potential of ekphrasis (Sawa, 2015).

The painting of Aristotle is animated both by the painter and the author of the novel - as soon as the author describes Rembrandt painting Aristotle's ears, the latter begins to hear; as soon as the artist paints the philosopher's eyes, the latter sees. The world presented in the novel is perceived through Aristotle's eyes, or, more precisely, through the animated representation of Aristotle painted on canvas by Rembrandt and described by Heller. This Aristotle is often bored, cold, angry or disappointed with the fact that people do not learn much from history and repeat the same mistakes. Still, Aristotle Contemplating a Bust of Homer is the prism through which the parallels between Hellenic culture and politics, on the one hand, and the culture and politics contemporary with Heller, on the other, are presented.

\section{Conclusion}

The notion of ekphrasis has the structure of a fold which joins but simultaneously makes a distinction between two such distant elements as word and image. The verbal and the visual constitute the ends or extremes of the fold's extension to each side. Ekphrasis as a fold, then, is a continuum of the verbal and the visual or the visual and the verbal. There is no hierarchy within a fold, and consequently within ekphrasis, and so there is no domination of one element over the other as the elements are indistinguishable. There is, hence, a chiastic balance and equality of the elements. The classical binary opposition between the visual and non-visual (the verbal) is replaced with the complementary and extendable functions of each element. Ekphrasis as fold can be extended into infinity, by means of another fold or folds, embracing, in the first place, the world presented in the literary work, to which a work of art described or mentioned belongs. By extension, it can unfold onto the topics and problems related to representing history. Ekphrastic historiographic metafiction uses non-verbal texts, or, to use Clüver's (2017) revised terminology, configurations in a non-kinetic visual medium (p. 462), either as a source of knowledge about the past, and as such as the starting point for telling a complex (fictionalised) story about the past, or a possible representation of the 
past, as exemplified by novels by Tracy Chevalier and Joseph Heller; or as the material to bridge the gaps in the otherwise fragmented and incomplete account of plausible past events, illustrated by examples from Rushdie's and Gale's novels.

\section{References}

Chevalier, T. (2000). Girl with a Pearl Earring. London: Harper Collins Publishers.

Clüver, C. (2017). Ekphrasis and adaptation. In T. Leitch (Ed.), The Oxford Handbook of Adaptation Studies (pp. 459-477). New York: Oxford University Press.

Currie, M. (Ed.) (2013). Metafiction. London, New York: Routledge.

Deleuze, G. (1993). The Fold: Leibniz and the Baroque (T. Conley, Trans.). London: The Athlone Press.

Fürher, H., \& Banaszkiewicz B. (2014). The trajectory of ancient ekphrasis. In A. Jedličková (Ed.), On Description (pp. 45-75). Prague: Akropolis.

Gale, P. (2008). Notes from an Exhibition. London, New York, Toronto, Sydney, New Delhi: Harper Perennial.

Hagstrum, J. H. (1987). The Sister Arts. The Tradition of Literary Pictorialism and English Poetry from Dryden to Gray. Chicago, London: University of Chicago Press.

Heffernan, J. (1991). Ekphrasis and representation. New Literary History, 22(2), 297-316.

Heffernan, J. (1993). Museum of Words. The Poetics of Ekphrasis from Homer to Ashbery. Chicago, London: University of Chicago Press.

Heffernan, J. (1996). Entering the museum of words. In P. Wagner (Ed.), Icons, Texts, Iconotexts: Essays on Ekphrasis and Intermediality (pp. 262-280). Berlin, New York: Walter de Gruyter.

Heller, J. (1988). Picture This. New York: G. P. Putnam's Sons.

Hutcheon, L. (1988). A Poetics of Postmodernism: History, Theory, Fiction. New York, London: Routledge.

Munster, A. (2006). Materializing New Media: Embodiment in Information Aesthetics. Hannover, London: University Press of New England.

Praz, M. (1974). Mnemosyne. The Parallel Between Literature and the Visual Arts. Princeton, London: Princeton University Press.

Rushdie, S. (2009). The Enchantress of Florence. London: Vintage.

Sawa, M. (2015). Ekphrasis in Modern British Fiction: A Pro-narrative Approach. Lublin: Wydawnictwo Katolickiego Uniwersytetu Lubelskiego.

Seppi, A. (2016). Simply complicated: Thinking in folds. In M. Friedman, \& W. Schäffner (Eds.), On Folding. Towards a New Field of Interdisciplinary Research (pp. 49-76). Bielefeld: transcript Verlag.

Smith, M. (1995). Literary Realism and the Ekphrastic Tradition. University Park: Pennsylvania State University Press.

Teyssot, G. (2000). Baroque topographies. Assemblage, 41, 79.

Wagner, P. (Ed.). (1996). Icons, Texts, Iconotexts: Essays on Ekphrasis and Intermediality. Berlin, New York: Walter de Gruyter.

West-Pavlov, R. (2009). Space as Theory: Kristeva, Foucault, Deleuze. Amsterdam, New York: Rodopi. 